\title{
Life Skills for Primary and Secondary School Children: Development of a Multilingual, Inclusive Education Program
}

\author{
Wiltrud Weidinger
}

Head of Centre for Teaching and Transcultural Learning, Zurich University of Teacher Education, Switzerland Corresponding Author: wiltrud.weidinger@phzh.ch

Citation: Weidinger, W. (2021). Life Skills for Primary and Secondary School Children: Development of a Multilingual, Inclusive Education Program. International Journal of Childhood Education, 2 (1), 12-22. https://doi.org/10.33422/ijce.v2i1.37

\begin{abstract}
The presented paper combines applied research and development in the field of cultural diversity and inclusive education. It addresses the improvement of primary and secondary school children's transversal skills through a specific personal development teaching and learning program and presents an ongoing study as an accompanying action-based research element. In a first step, the theoretical international frameworks for life skills and inclusive education programs are discussed and combined with the claim for lifelong learning and the need for making pre-existing competencies visible. The presented personal development program tackles individual learning processes and transversal skills and shifts the teaching and learning culture towards child-oriented and cooperative learning. This shift can bear challenges for teacher trainers, teachers, students, and the entire educational system as belief systems, traditions, standard teaching practices, and the individual child's view are under change. In a second step, the development of the inclusive personal development program is discussed, focusing on the participatory process and stakeholders of the three partner countries Kosovo, North-Macedonia, and the Republic of Moldova. Alignment to curricula, integration into curricula, development of teaching and learning material, and training programs are presented as relevant issues and stepstones. The personal development teaching and learning material for grades one to nine is explained as an open-source material in different languages. In a third step, the ongoing action-based research study is presented and discussed, highlighting the first results and consequences for the development of teaching and learning materials and training programs.
\end{abstract}

Keywords: inclusion; international cooperation; personal development; transversal skills; teacher training

\section{Introduction}

Over the past years, educational systems in various European countries have adapted and reformed their curricula to support disciplinary competencies and transversal skills. Teaching and learning shall contribute to a substantial personal development for mastering different situations in a school context and a future work context. The changes in these curricula range from cross-curricular principles that outline competencies in social, methodical, and selfrelated learning areas (Switzerland) to separate school subjects that deal with personal development itself (Republic of Moldova) or specific subjects training pre-vocational skills (Kosovo, North-Macedonia). All these curricula focus on strengthening primary and secondary school students in their various pre-existing competencies and skills for a future engagement in the labor market and society in total. Lifelong learning becomes essential, and the desired goal is to equip students with the skills needed to succeed in the $21^{\text {st }}$ century. This focus can also be described as a reaction to international organizations' frameworks and the

(C) The Author(s). 2022 Open Access. This article is distributed under the terms of the Creative Commons Attribution 4.0 International License, which permits unrestricted use, distribution, and redistribution in any medium, provided that the original author(s) and source are credited. 
corresponding trends in policymaking, reforming curricula, and preparing a country's student population to newly arising demands.

\subsection{International Frameworks}

In the light of rapidly changing societies, in environmental, economic, and social aspects, the OECD Learning Framework 2030 supports the need for broader educational goals (OECD $2018,3)$. Individual, as well as collective well-being, are in the focus of this future vision assigning education a crucial role in approaching these goals: "Education as a vital role to play in developing the knowledge, skills, attitudes, and values that enable people to contribute to and benefit from an inclusive and sustainable future. Learning to form clear and purposeful goals, work with others with different perspectives, find untapped opportunities, and identify multiple solutions to big problems will be essential in the coming years. Education needs to aim to do more than prepare young people for the world of work; it needs to equip students with the skills they need to become active, responsible, and engaged citizens." (ibid, 4)

The call for an inclusive education that puts the learners into the center of their learning and a personalized environment that supports and motivates each student, makes connections between different learning experiences and enables students to design their learning processes in collaboration with others (ibid, 4). The competencies and skills that students shall acquire for the development of their personality are transversal skills or life skills that become necessary in different disciplinary and non-disciplinary learning situations. However, the concept of life skills education per se is not a new one. Already in 1998, the World Health Organization defined life skills as "the abilities for adaptive and positive behavior that enable individuals to deal effectively with the demands and challenges of everyday life" (WHO 1999). The WHO life skills lie in decision-making, problem-solving, creative thinking and critical thinking, communication and interpersonal skills, self-awareness, empathy, coping with emotions and coping with stress (WHO 1999, 1).

UNICEF similarly defines life skills, putting them into an A-S-K model of competencies: "a behaviour change or behaviour development approach designed to address a balance of three areas: knowledge, attitude and skills". UNICEF bases its definition on research evidence that suggests that shifts in risk behavior are unlikely if knowledge, attitudinal, and skills-based competency are not addressed (United Nations, 2006, 1). When broken down into concrete skills, the skills described by UNICEF, UNESCO, and WHO list the ten core life skill strategies and techniques as: problem-solving, critical thinking, effective communication skills, decision-making, creative thinking, interpersonal relationship skills, self-awareness building skills, empathy, and coping with stress and emotions (United Nations, 2006, 1).

\subsection{Inclusive Education}

The claims of international frameworks tie in with several principles identified in the discourse on inclusive education programs that focus on transforming disadvantaged, marginalized or vulnerable children's current life chances through education (Hollenweger 2020, 3). Modern pedagogical literature sees pillars such as having a learner-centered vision of education top-of-mind for any decision taken, including being in-line with a capability approach to education (Robeyns, 2006). Capabilities are understood as the "genuine opportunities or freedoms to realize these functionings" (ibid.). This understanding adds the dimension of self-efficacy, autonomy, and personal choice as a criterion (Hollenweger 2020, $3)$. Therefore, a learner-centered vision of education is not only about performance but about the competencies to make meaningful and positive choices about one's own life and future (ibid.). Other principles highlight teachers' empowerment to implement high-quality inclusive practices, including questions of curricula, planning and assessment practices, and structural 
questions such as physical environment, student-teacher ratios, or teacher qualifications (Love \& Horn 2019). Inclusive classroom practices should directly support students' learning; assessment practices should support learning and development and provide guidance and direction for future learning and not hinder future chances (Hollenweger 2020, 4). Cooperation and collaboration among different stakeholders in schools and with professionals, with parents or the wider community, are identified as another key aspect of supporting inclusive education programs and not leaving teachers as isolated agents for inclusion. It is the call for a collective self-efficacy - a sense of achieving something valuable together, which will have a positive impact on student achievement (ibid.). An enabling context for inclusive practices forms the last of an identified key factor for successful inclusive education programs, especially in underprivileged regions, according to one of the last reports of UNICEFs inclusive education strategies (ibid.). In this respect, enabling contexts are understood as "solidified practices," reflected in social structures, processes, and customs that endorse and support inclusive classroom practices (ibid.). It includes regulatory components such as laws, social welfare or legislative processes, and normative components such as professional standards, work ethos, belief systems and mindsets, and culturalcognitive components such as social attitudes that a society or the organization's members hold (Scott 2008). According to the latest UNICEF report (Hollenweger 2020), a study from Kosovo (Zabeli et al. 2020) highlights the need for changes at all levels: Expectations and organization of schooling, curriculum to recognize all student identities, pedagogy, and assessment for developing students' potentials and the culture of schools for embedding them in a community.

\subsection{A Lifelong Learning Perspective}

Apart from focusing on transversal skills for developing one's competencies, skills, and attitudes, and the claim for high-quality inclusive education programs, the concept of lifelong learning becomes once more highlighted. In an academic debate, competence orientation is frequently connected to lifelong learning and acquiring appropriate life skills at school (Weidinger 2014). This tendency can also be traced in the papers published by the European Commission: "It is where they gain the basic knowledge, skills, and competencies that they need throughout their lives and the place where many of their fundamental attitudes and values develop" (European Commission 2010). As a result, the demand has arisen for teachers to be equipped with the necessary competencies to orient students' learning towards a lifelong perspective (Weidinger 2014). The undertakings of the various countries are diverse; thus, a majority of teachers admit to not having sufficient belief in their self-efficacy to be able to equip pupils with the necessary competencies: "teachers report a rather low personal self-efficacy concerning their possession of the competencies needed to encourage their pupils' LLL [lifelong learning] competences" (Spiel \& Schober 2002; Hadré \& Sullivan 2008). Research shows that in underprivileged regions in which educational policy did not address this particular need that teachers manifested signs of an acute conviction of this lack of personal self-efficacy and that this, in turn, had a direct impact on their students.

The competencies connected to lifelong learning demands are to do with learning motivation, a conviction of self-efficacy, teamwork skills, information and research competence, flexibility, communication competence, etc. The Centre for Teaching and Transcultural Learning of the Department International Projects in Education of the Zurich University of Teacher Education concludes that this encompasses the OECD Learning Framework 2030 consisting of knowledge, skills, attitudes, and values to meet complex demands (OECD 2018, 5).

In the light of these campaigns, educational policies and curricula have been reformed in various regions. For many countries, such as the participating partner countries in this study, the shift from content-related learning goals focusing on acquiring knowledge towards 
competencies bears a challenge, and filling curricula with possible contents, methods, and related materials can also be full of questions. Following the claims of international frameworks, inclusive education practices, and lifelong learning perspectives discussed above, the exemplary process for developing this personal development program is discussed in the following chapters of this paper.

\section{Development of the Inclusive Personal Development Program}

\subsection{Pre-Existing Competencies as a Starting Point}

In the vision of a personal development program aimed at individual strengths and areas of development, students' pre-existing competencies and connecting to these competencies in school are essential elements of a social-constructive understanding of learning (Berner et al 2018). In regions with a very diverse student population with students from different ethnic, cultural, and language backgrounds or with disadvantaged students for socio-economic reasons, school curricula for personal development shall focus even more on using strengths and building on these strengths. Children coming from minorities or vulnerable groups within a society are often disadvantaged because of their ethnic backgrounds and difference from the others and because of limited access and attendance to school (UNICEF 2007a, 2007b), (Surdu et al 2011). However, this does not mean that these children start school as a tabula rasa with no prior acquired competencies and skills (Weidinger 2016). On the contrary, children who grew up in socio-economically vulnerable situations often contribute to the family's survival. They enter the schools with competencies and skills that they have acquired in non-formal educational settings, in their families, in the peer-group, on the streets etc. The educational system misses to perceive, measure, and value these pre-existing competencies (ibid.). Schools often do not offer opportunities where these pre-existing competencies and skills can be applied, tested, further developed, and transferred into a way that they become useful and accepted by the institution and its requirements. These pre-existing competencies often encompass the described life skills. However, they also include purely subject-related competencies such as calculating, verbal communication skills (when selling things), technical skills (repairing, agricultural work, handicrafts), as well as knowledge about their environment and its materials (agricultural work, weather forecasts etc.). In schools, children with such pre-existing or pre-acquired competencies cannot show and prove them as they are not part of school tasks, tests, or other forms of summative assessment procedures (ibid.). This is also why underprivileged or marginalised children - when placed in mixed groups with children of the major population - quickly become stigmatized (ibid.). Their perceived lack of cognitive skills becomes visible in the context of the classroom also to their colleagues. Therefore, school not only serves for the development of the needed cognitive life skills such as problem-solving, critical thinking, or decision-making skills but becomes an important motor in promoting empathy, emotional awareness, and training conflict-resolution skills. School becomes a place of including and supporting everyone, regardless of their socio-economic background, academic achievement, or cultural heritage.

\subsection{Contextual Conditions and Alignment to Curricula}

\subsubsection{Partners and Stakeholders}

The personal development program and its applied research study were carried out by the Zurich University of Teacher Education, Department of International Projects in Education. The program is financed by the Canton of Zurich. The program is being implemented in three countries, the Republic of Moldova, North-Macedonia, and Kosovo. In all three countries, the project partners are the Ministries of Education and for operative implementation independent NGOs or project coordinators who secured all involved stakeholders' working process and participation. A phase of thorough planning, assessment 
of needs, and mapping of other activities in this thematic field was undertaken in 2019 in all regions with a kick-off for starting the development of teaching and learning materials in fall 2019. In all phases of the project, Swiss experts worked very closely together with the three countries' core-teams, consisting of experts in teaching and learning material development, curriculum development, pre- and in-service teacher training, and pedagogy/educational psychology. The Personal Development study is carried out as an accompanying element along the entire process.

\subsubsection{Alignment to Curricula}

The teaching material and training program for personal development was aligned to existing and partly new curricula in all partner countries. Along with these curricula, the competencies were analyzed and developed into a competence framework. They include different spheres of personality, such as:

- Cognitive skills such as problem-solving skills, creative thinking skills, critical thinking skills, and metacognitive skills;

- Social skills such as communication and cooperation skills, interpersonal relationship skills, and empathy;

- Self-awareness skills such as self-responsibility, decision-making skills, and selfreflection skills;

- Emotion-regulating skills such as dealing with emotions, dealing with stress and conflict-solving skills.

Personal development and life skills education is embedded in all school subjects and is always connected to learning content relevant to the individual at their current state of development (Weidinger et al. 2020). The content and tasks in this personal development program are targeted at different age groups and grades. Throughout the curriculum of compulsory schooling, teaching life skills becomes more complex, following similar topics each year and focussing on the same skills throughout the entire time at school (ibid.). Thus, life skills education is built up progressively from an early age onwards, starting at the entry point into the school system at kindergarten or primary school and lasting until the end of compulsory education. During the students' school lives, personal development skills are taught through a spiral curriculum: they are repeated each school year, but each time at a more complex level. The spiral curriculum of personal development and life skills education can be described as an approach that presents different key concepts for learning with increasing complexity levels throughout progressive school years. Following the paradigm of the early educationalist and psychologist Jerome Bruner that "any subject can be taught effectively in some intellectually honest form to any child at any stage of development" (Bruner 1960), the spiral curriculum is the underlying pedagogical principle of this program. Information, topics, and tasks are introduced to children at a young age and continually reintroduced, reinforced, and built upon. Not only will proficiency in the different life skills be developed in an adaptive learning method, but the meaning and significance of what is taught also become an integral part of the program. This spiral curriculum includes ideas, principles, and values significant to the students as they mature and values essential to broader society. Through the spiral curriculum, the program also follows the approach and paradigm of life-long learning (Weidinger et al. 2020).

\subsection{Development of Teaching and Learning Material}

2.3.1. The Structure of the Personal Development Teaching and Learning Materials

In the presented personal development program, life skills are taught in five modules that comprise key concepts (Weidinger et al. 2020). These are:

1. Self-knowledge and knowledge of others emphasizing self-knowledge and self-esteem, exploration and self-evaluation of personal resources, family as a value: responsibilities, 
gender roles, stereotypes, assertiveness, non-conflictual and non-violent communication, volunteering etc

2. Ensuring quality of life with an emphasis on integrity, efficient resource management, sustainable development, good self-management, etc.

3. Healthy lifestyles guiding students on issues related to physical and emotional health, healthy food, counteracting vices such as drugs, alcohol, smoking, gender influences, etc

4. Designing personal careers and developing entrepreneurial mindsets with an emphasis on occupational understanding from a labor market perspective, career planning, and career decision making, entrepreneurship as a career option, etc.

5. Personal safety focusing on behavior to ensure personal safety and the safety of others.

Following the spiral curriculum, each manual in this series from grades one up to 12 uses the same modules and key concepts. The tasks are spread out over one school year, with four tasks per module. Each manual, therefore, consists of 20 tasks altogether. However, students' topics and tasks often overlap: a talk about a healthy lifestyle will touch on ensuring the quality of life and the art of self-knowledge; a task-centered on career options for older children will also touch on self-knowledge and ensuring the quality of life etc. Therefore, while the tasks are organized into five modules, they cannot be viewed as entirely separate (ibid). The modular approach insists on an educational intervention characterized by integrating knowledge, skills, and attitudes specific to competencies development. The integrative approach is applied within each module, capitalizing on gains made in other school subjects or the student's social and familiar environment. In this way, the Personal Development course is centered on the development of competencies with a specific focus on values, attitudes, and dispositions and, more importantly, it aims at bringing each child or adolescent in his/her zone of proximal development by setting tasks that are challenging enough to enable learning processes but adequate to also make successes possible (Vygotsky 1978). The teaching and learning materials are manuals for teachers with concrete hints and ideas and small templates for classroom implementation. Goals and competencies and all didactic steps and hints for the social settings and learning forms are visible on one page for direct use in the classroom.

All booklets of the personal development program are translated from English into Romanian, Albanian, Macedonian, Serbian and Russian and will be soon available on IPE's textbook website https://ipe-textbooks.phzh.ch/ for free download and use. Currently, the teaching material for grades 1 to 4 is in finalization, grades 5 to 9 are ready to use, and grades 10 to 12 are in development.

\subsection{Development of Training Programs}

The development of training programs was started in 2019, together with all partners. Whereas in the Republic of Moldova, all training programs were aligned not only with the implementing project team, but they were also coordinated and approved by the Ministry of Education; in North-Macedonia and Kosovo, two NGOs, mandated for in-service training of teachers, were already mandated by the relevant authorities in their country. The developed training sessions consist of different modules delivered partly in a face-to-face session in the three countries' local context and partly via online courses due to the COVID-19 situation. Target groups of the training program were teachers, school principals, NGO staff for the organization of in-service training for teachers, University staff for integration into existing study programs in education, and staff of educational authorities for the organization of inservice training for teachers. The target groups differed from one country to another, depending on the specific allocation of tasks and responsibilities for in-service training. The 
modules were conducted in English or were translated into Macedonian or Romanian. In Kosovo, all participants spoke English.

The modules consisted of the following topics:

- Introduction to life skills

- Pedagogic and psychological background knowledge about life skills and personal development

- Introduction to the teaching and learning materials

- Didactical approaches and teaching methods

- Accompanying of learning processes and assessment

- Reflection of one's own teaching

- Designing own life skills lessons

All modules were set up in a structure that combines short inputs of information with active discussion and reflection elements. In cases of face-to-face training, model lessons or microteaching sequences were used.

\section{Methodology and Working Process}

The accompanying study has been done as a follow-up to the completed study of developing a similar program (FACE) in 2016 (Weidinger 2016). The research component of FACE included a pre-post-test design and followed a mixed-method approach (Caracelli \& Greene 1993). Whereas in the FACE study, a mixed-method design was used to gather results about improving the students' self-concept, adopting the material, and implications for future material, the Personal Development study takes a more participatory approach. It uses some FACE results, especially for designing the teaching and learning materials and the training for teachers and other multipliers. All methods used in the personal development study follow an action-research approach using only qualitative methods for data gathering and interpretation (McTaggart, 1997, 2006). The scientific method of theory building is grounded theory (Glaser \& Strauss, 1967, 2008), (Strauss \& Corbin, 1990). In the context of development cooperation, the approach used can also be described as an evidence-based action research approach (Popplewell \& Hayman, 2012).

The categories for analysis and interpretation include the following dimensions:

- teaching material development: competence orientation, teaching methods, didactic hints for teachers, gender, cultural dimension

- training program for teachers: knowledge, teaching methods, attitudes, reflection

The personal development program's working process can be described as a participative process on eye-level with teaching and learning material development experts from the Republic of Moldova and experts for developing training programs for pre- and in-service teachers from North-Macedonia, Kosovo, and the Republic of Moldova ( $n=9)$. Protocols of exchange meetings, written feedback on the teaching and learning material, and feedback directly in the different manuals served as a data source for the analysis. For specific evaluation of the training programs' individual modules, separate quantitative evaluations were conducted by the implementing partners through online surveys (participants $n=69$ ).

\section{Obtained Results and Discussion}

The accompanying research study results are interesting and give important insights into a future adaptation of the program. The following results were derived from the qualitative analysis of the discussions and feedback rounds with experts and teachers to develop teaching materials. Data gathered after training sessions through questionnaires and feedback rounds were used to develop the training programs (IPE 2020). 


\subsection{Development of Teaching Material}

Competence orientation: Tasks in the teaching and learning material are formulated by addressing competencies aligned with the curricula. In developing the teaching and learning material, experts' and teachers' feedback showed that the curricula had not clarified an orientation towards competencies. Teachers as well as student teachers tend to stick to content-related goals or express the need for a topic rather than focussing on the competencies of students to be developed. Curriculum experts and authors expressed this quite clearly despite the adapted and reformed curricula.

Teaching methods: Teachers seem to be familiar with most teaching methods such as cooperative learning, project-oriented learning, or task-based learning. However, they report experiences to be limited to special occasions where these are applied. Only cooperative learning elements are experienced in the framework of the existing curriculum and the corresponding teaching and learning materials. The future focus should be given to a self-evident integration of different inclusive teaching practices as part of teachers' professional identity. Moreover, even if teachers know a particular teaching method or didactic approach, the quality of practice in their daily teaching remains unclear.

Didactic hints for teachers: Practical hints for teachers on classroom organization, social settings, leading discussions, or how to give feedback to students and parents were welcomed and applied. However, in developing the teaching and learning material, it became evident that teachers seem to lack self-efficacy and trust in their competencies as moderators, facilitators, and classroom managers. This seemed to pose a dilemma as, on the one hand, the need for concrete hints arose, especially in areas of how to promote critical thinking processes, expression of own opinions, and self-organization of students (formulated mainly by curriculum experts and authors) but on the other hand too close instructions again would hinder self-responsibility and autonomy of teachers. There seems to be a high demand on focussing on this change of teaching and learning culture.

Gender: Gender dimensions are addressed in various tasks within the teaching and learning materials, especially in topics revolving around identity, life quality, respect towards others, and health. A mutual discussion was addressed in elaborating different forms of families (core family versus single-parent families or same-gender families). It became evident that addressing gender issues apart from male and female gender is difficult in some partner countries. The same applies to the visual representation of different forms of families or rainbow families. Even though teaching material and curriculum experts see this as a necessary topic, addressing this officially in teaching and learning materials for teachers and students becomes a political issue.

Cultural dimension: All tasks and hints in the textbooks are formulated in a culturally neutral way. However, when trying to connect to the individual lives of children nowadays, cultural variations become apparent. These variations are not limited to a specific country's cultural background and heritage but arise more from families' very different socioeconomic backgrounds or their underprivileged life situations. Adaptations on tasks that focus partly on resources at home (e.g., toys, digital toys, books, etc.) were discussed and re-formulated.

\subsection{Development of Training Programs}

Knowledge: Lecturers and teachers in all partner countries welcomed training parts revolving around background knowledge of education, life skills, and pedagogical or psychological insights from educational science. It became evident that there is a great interest to connect implementation in schools to theoretical knowledge about the topic as an element of individual lifelong learning. Out of the already evaluated questionnaires, over 80 $\%$ of the participants rated this part as very valuable or valuable. 
Teaching methods and skills: As already evident in the development of the teaching and learning material, the training parts on teaching methods or classroom skills were valued but with a broader distribution. $60 \%$ of all participants regarded this element as very helpful for themselves, $30 \%$ as helpful, and $10 \%$ were only rated as "satisfactory". Interpretations of these results can be made in different directions. On the one hand, parts of the practitioners are familiar with the presented cooperative, project-oriented, or task-based teaching methods and practice them in their daily business; on the other hand, there might be familiarity, but at the same time, a limitation in actual application to special events. Because of the COVID19 situation, the training took place mainly online, making it more difficult to work with micro-teaching settings or real-life methodical training elements. For future training, this poses the biggest challenge in bringing the idea of high-quality inclusive teaching practice to the ground.

Attitudes: In training sessions that addressed questions of accompanying learning processes and assessing students' achievement, teachers' attitudes played an important role. Even though personal development is integrated into most curricula in a child-oriented and crosscurricular way, teachers feel the pressure to gather enough data for a summative assessment of students' learning. It is an invisible pressure that lies on teachers pushing them into a dilemma situation of installing an individual and child-oriented learning atmosphere and at the same time asking for a concrete product at the end of each teaching session that can be evaluated and graded. It became evident that it is also connected to students' participation, feedback to students, and parents' feedback.

Reflection: A separate training part focussed on the planning and reflection of personal development lessons. Working with different planning and reflection models prompted indepth discussions about the possible reflection level for teachers and students in personal development lessons. The discussions showed high demand by lecturers and teachers to focus more on this area of teaching practice. Some participants stated another need, mostly teacher students: the need to integrate personal development modules already in teacher pre-service training institutions and to focus not only on their future students but on their own personal development as well. According to this group, the demand is very high, leaving teacher pre-service training institutions in the light of theory-based training institutions.

\section{Conclusion}

The Republic of Moldova, North-Macedonia, and Kosovo's development program is still ongoing, aiming at broader dissemination in the coming years. The accompanying research study gave concrete implications for all three countries' project teams on how to proceed. Along these lines, the following assumptions were drawn and partly completed or started:

Development of teaching and learning materials:

- Competence-orientation in all manuals was reworked, tasks were re-formulated, and the training program was focused on differentiating goal-orientation from competenceorientation.

- Teaching methods were explained in the manuals, and a closer focus will be put on the actual implementation of different inclusive teaching practices during the upcoming training.

- Concrete examples enriched didactic hints for teachers by authors of the local context.

- Gender formulations were re-formulated to allow teachers to prepare themselves better for leading discussions or encouraging critical thinking processes in this respect. Instructions for sensitive handling of similar situations were given in the manuals.

- Tasks that rely too closely on an average socio-economic situation were taken out of the manuals instead of tasks that do not explicitly refer to additional resources. 
Training program:

- A didactic guide was produced alongside the training as an additional element for participants focussing on theoretical background knowledge and didactic approaches to personal development lessons.

- A clear focus will be put on teaching and reflection methods for teachers and student teachers, including their own micro-teaching sequences in the upcoming training.

- Training in accompanying learning processes and assessment procedures will include more prominent elements of professional identity, attitudes, subjective beliefs, and student-orientation. A strong focus will be put on defining and analysing roles of teachers in a changed teaching and learning culture.

- With pre-service teacher training institutions, implementation plans for integrating personal development in existing modules as part of a professional and personal reflection for teacher students will be made.

In the remaining three years of cooperation, the focus will be put on making the necessary adaptations and implementing the program nationwide. This includes carrying on the inservice training for teachers of grades $1-12$ and bringing pre-service teacher training institutions on board to implement the program in their modules on inclusive education and personal development classes.

\section{References}

Berner H., Isler, R. and Weidinger, W. (2018). Simply good teaching. hep: Bern.

Bruner, J.S. (1960). The process of education. Cambridge: Harvard University Press.

Caracelli, V.J. and Greene, J.C. (1993). Data analysis strategies for mixed-method evaluation designs. Educational Evaluation and Policy Analysis, 15 (2), pp. 195-207. https://doi.org/10.3102/ $\underline{01623737015002195}$

European Commission (2010). School education: Equipping a new generation (Doc 64). [Online]. Available: http://ec.europa.eu/education/lifelong-learning-policy/doc64_en.htm.

Glaser, B.G. and Strauss A.L. (1967). The discovery of grounded theory: strategies for qualitative research. New York: Aldine de Gruyter. https://doi.org/10.1097/00006199-196807000-00014

Glaser, B.G. and Strauss, A. L. (2008): Grounded Theory: Strategien qualitativer Forschung. (Nachdruck der 2., korr. Auflage). Bern: Huber (Orig. 1967).

Hadré, P., Sullivan, D.W. (2008). Teacher perceptions and individual differences: how they influence rural teachers' motivating strategies. Teaching and Teacher Education, 24 (8), pp. 2059-2075. https://doi.org/10.1016/j.tate.2008.04.007

Hollenweger, J. (2020): Specialist Provision. Draft report submitted to UNICEF.

IPE - International Projects in Education (2020): PEACOCK, JOBS Moldova research protocols and training evaluations. Internal Working papers. Zurich University of Teacher Education.

Love, H.R. and Horn, L. (2019). Definition, Context, Quality: Current Issues in Research Examining High-Quality Inclusive Education. [Online]. https://doi.org/10.1177/0271121419846342

McTaggart, R. (1997). Participatory action research: international context and consequences. SUNY Series in teacher preparation and development. Boulder, Colo.: Netlibrary, Inc., 1999.

McTaggart, R. (2006). Participatory Action Research: issues in theory and practice. Educational Action Research, 2:3, pp. 313-337, [Online]. https://doi.org/10.1080/0965079940020302

OECD (2018). The future of education and skills. Education 2030. The future we want. [Online]. Available:https://www.oecd.org/education/2030/E2030\%20Position\%20Paper\%20(05.04.2018).pdf

Popplewell, R. \& Hayman, R. (2012): Where, how, and why are Action Research approaches used by international development non-governmental organisations? INTRAC, Briefing Paper 32. 
[Online]. Available: https://www.intrac.org/wpcms/wp-content/uploads/2016/09/Briefing-Paper32-Where-how-and-why-are-Action-Research-approaches-used-by-international-developmentnon-governmental-organisations-2-1.pdf

Robeyns, I. (2006). The capability approach in practice. The Journal of Political Philosophy. Volume 14, Number 3, 2006, pp. 351 - 376. [Online]. https://doi.org/10.1111/j.1467-9760.2006.00263.x

Scott, W.R. (2008). Institutions and Organizations: Ideas and Interests. 3rd ed. Sage Publications, Los Angeles, CA.

Spiel, C. and Schober B. (2002). Zusammenfassung des Projekts "Lebenslanges Lernen als Ziel: Welchen Beitrag kann die Schule zum Aufbau von Bildungsmotivation leisten?" Erziehung und Unterricht, 152 (9-10), pp. 1271-1281, öbv.

Strauss, A.L, Corbin, J.M. (1990). The basics of qualitative research: grounded theory procedures and techniques. Newbury Park, CA: SAGE.

Surdu, L., Vincze, E. and Wamsiedel, M. (2011). Roma School Participation, Non-Attendance and Discrimination in Romania. Romani Criss \& UNICEF. UNICEF: Bucarest.

United Nations (2006). Module VII - Life Skills. [Online]. Available: https://www.unodc.org/pdf/ youthnet/action/message/escap_peers 07.pdf

UNICEF (2007a). Breaking the Cycle of Exclusion. Roma children in South East Europe. Unicef Serbia: Belgrade. [Online]. Available: https://www.unicef.org/serbia/en/reports/breaking-cycleexclusion

UNICEF (2007b). Romani Children in South East Europe. The challenge of overcoming centuries of distrust and discrimination. Regional Office for CEE/CIS. Discussion Paper ISSUE 7. United Nations: Geneva. [Online]. Available: https://reyn.eu/wp-content/uploads/2017/11/RomaniChildren-in-SEE.Overcoming-Centuries-of-Distrust.pdf

Vygotsky, L. S. (1978). Mind in society: The development of higher psychological processes. Cambridge: Harvard University Press.

Weidinger, W. (2014): Competence-oriented teaching in international projects. In: Rabensteiner, P.M. (2014): Interculturality. Internationalization in Teacher Education. Vol. 2, pp. $34-49$. Baltmannsweiler: Schneider Verlag Hohengehren.

Weidinger, Wiltrud (2016): Self-competences and life skills of children coming from vulnerable groups - Research-based development of an inclusive education program. Proceedings of European Conference for Education ECE. Brighton, United Kingdom, pp. 21 - 34.

Weidinger, W. et al. (2020): A Teacher's Guide in Personal Development. Grade 5. International Projects in Education. Zurich University of Teacher Education. [Online]. Available: https:/ipetextbooks.phzh.ch/globalassets/ipe-textbooks.phzh.ch/english/personal_development_grade_5 en_ro def.pdf.

World Health Organisation (1999). Partners in Life Skills Education. Conclusions from a United Nationals Interagency Meeting. Geneva: World Health Organisation. [Online]. Available: https://www.who.int/mental health/media/en/30.pdf

Zabeli, N., Perolli-Shehu, B. and Gjelaj, M. (2020). From Segregation to Inclusion: the Case of Kosovo. 12(2), pp. 201-225. [Online]. http://dx.doi.org/10.14658/pupj-ijse-2020-2-9 